Check for updates

Cite this: Nanoscale Adv., 2019, 1, 3686

\title{
Ceria/cobalt borate hybrids as efficient electrocatalysts for water oxidation under neutral conditions $\uparrow$
}

\begin{abstract}
Xuemei Zhou, ${ }^{a}$ Sijia Guo, ${ }^{a}$ Qiran Cai (D) ${ }^{b}$ and Shaoming Huang (D) *a
Oxygen evolution reaction (OER) catalysts are of importance for electrochemical water splitting and fuel generation. Despite enormous efforts, the design and development of OER catalysts with high catalytic activities under neutral conditions are highly desired but still remain a great challenge. Herein, we report a room temperature chemical route to prepare $x$ ceria/cobalt borate $\left(x \mathrm{CeO}_{2} / \mathrm{Co}-\mathrm{Bi}\right)$ hybrids as efficient OER catalysts by tuning the molar ratio of $\mathrm{Ce} / \mathrm{Co}\left(x\right.$ represents the amount of $\mathrm{CeO}_{2}$ ). The optimised catalyst $\left(2 \mathrm{OCeO}_{2} / \mathrm{Co}-\mathrm{Bi}\right.$ hybrid) was found to exhibit remarkable OER catalytic activity with an overpotential of $453 \mathrm{mV}$ at a current density of $10 \mathrm{~mA} \mathrm{~cm}{ }^{-2}$. Tafel slope of $120 \mathrm{mV} \mathrm{dec}^{-1}$ and long-term stability in neutral medium due to its good conductivity, mass transportation and strong synergetic coupling effects, showing the potential of Co-based electrochemical materials for practical application in energy storage devices.
\end{abstract}

Received 5th June 2019

Accepted 18th July 2019

DOI: 10.1039/c9na00356h

rsc.li/nanoscale-advances

However, their high cost, scarcity, and the requirement for

\section{Introduction}

Many efforts have been made to explore alternative energy storage and conversion systems to solve the increasing environmental problems and energy crisis. ${ }^{1-3}$ Hydrogen has been considered as a clean alternative energy due to its high energy output and carbon-neutral combustion products, ${ }^{2,4}$ and electrochemical water splitting is thought to be a promising technology to convert electrical energy into chemical fuels for hydrogen storage..$^{5-7}$ However, the oxygen evolution reaction (OER) significantly affects the overall water-splitting efficiency due to its sluggish kinetics with an energy-intensive reaction and high overpotential. ${ }^{8-11}$ Although many electrocatalysts have been explored to achieve high current density at low overpotentials and expedite the OER reaction kinetics process, ${ }^{8,9,12,13}$ noble metal oxides (e.g. $\mathrm{RuO}_{2}$ or $\mathrm{IrO}_{2}$ ), operating in acidic or alkaline solutions, are the most active OER electrocatalysts.

${ }^{a}$ School of Material and Energy, Guangzhou Key Laboratory of Low Dimensional Materials and Energy Devices, Guangdong University of Technology, Guangzhou, 51006, P. R. China. E-mail: smhuang@gdut.edu.cn

${ }^{b}$ Institute for Frontier Materials, Deakin University, Geelong Waurn Ponds Campus, Victoria, 3216, Australia

$\dagger$ Electronic supplementary information (ESI) available: SEM, TEM, XRD and SAED of Co-Bi nanosheets, EDS mapping images, EEIS spectrum of $20 \mathrm{CeO}_{2} / \mathrm{Co}-\mathrm{Bi}$, nitrogen adsorption/desorption isotherms of as-grown products (Co- $\mathrm{Bi}, 10 \mathrm{CeO}_{2} / \mathrm{Co}-\mathrm{Bi}, 20 \mathrm{CeO}_{2} / \mathrm{Co}-\mathrm{Bi}$ and $30 \mathrm{CeO}_{2} / \mathrm{Co}-\mathrm{Bi}$ composites), CVs of all the samples $\left(\mathrm{Co}-\mathrm{Bi}, \quad 10 \mathrm{CeO}_{2} / \mathrm{Co}-\mathrm{Bi}, \quad 20 \mathrm{CeO}_{2} / \mathrm{Co}-\mathrm{Bi}\right.$ and $30 \mathrm{CeO}_{2} / \mathrm{Co}-\mathrm{Bi}$ composites), impedance Nyquist plots of $\mathrm{Co}-\mathrm{Bi}, 10 \mathrm{CeO}_{2} / \mathrm{Co}-\mathrm{Bi}, 20 \mathrm{CeO}_{2} / \mathrm{Co}-\mathrm{Bi}$ and $30 \mathrm{CeO}_{2} / \mathrm{Co}-\mathrm{Bi}$ composite electrodes. CVs of the $20 \mathrm{CeO}_{2} / \mathrm{Co}-\mathrm{Bi}$ composite electrode, comparison of the OER activities of cobalt-based catalysts in neutral medium listed in Table S1. See DOI: 10.1039/c9na00356h extreme $\mathrm{pH}$ conditions have greatly hindered the large-scale application of these OER catalysts. ${ }^{12,14-16}$ Therefore, it is highly desirable to develop effective non-noble metal OER catalytic alternatives to improve the efficiency of water oxidation in a near-neutral environment.

Oxygen-evolving complexes composed of manganese and calcium are well known as natural water-splitting complexes. ${ }^{17,18}$ Inspired by this thought, a new category of artificial water oxidation electrocatalysts with amorphous features consisting of metals (such as nickel and cobalt), oxygen, and inorganic borate, namely nickel-borate ( $\mathrm{Ni}-\mathrm{Bi}$ ) or cobalt-borate (Co-Bi), has attracted significant attention due to their low cost, high intrinsic activity, and superior stability. ${ }^{13,14,19-22}$ For example, Nocera et al. reported that a nickel-borate (Ni-Bi) film, electro-deposited on indium tin oxide (ITO), had high catalytic activity towards electrochemical water oxidation under nearneutral conditions, achieving a current density of $1 \mathrm{~mA} \mathrm{~cm}{ }^{-2}$ in $0.1 \mathrm{M}$ borate buffer at an overpotential of $425 \mathrm{mV} .{ }^{19} \mathrm{~A}$ nickelborate nanoarray supported by carbon cloth $(\mathrm{Ni}-\mathrm{Bi} / \mathrm{CC})$ yielded a geometrical catalytic current density of $10 \mathrm{~mA} \mathrm{~cm}{ }^{-2}$ at an overpotential of $470 \mathrm{mV} \cdot{ }^{14}$ Recently, amorphous Co-Bi ultrathin nanosheets were designed for electrochemical water oxidation under neutral conditions. ${ }^{13,23}$ However, the application of $\mathrm{Co}-\mathrm{Bi}$ as a catalyst is limited by its poor OER kinetics and mass transfer ability, which can be solved by adding OER co-catalysts.

As one of the most important rare earth oxides, ceria $\left(\mathrm{CeO}_{2}\right)$ has been usually used in the electrochemical field due to the following advantages: ${ }^{7,24-27}$ (i) flexible transition between the $\mathrm{Ce}^{3+}$ and $\mathrm{Ce}^{4+}$ oxidation states, which can provide the opportunity to generate strong electronic interactions with other 
matrices and therefore probably improves the catalytic performance; (ii) good electronic/ionic conductivity, which can improve charge transfer and promote the reaction process; (iii) reversible surface oxygen ion exchange, which will absorb $\mathrm{O}_{2}$ produced during the OER and enhance the OER activity; (iv) large oxygen-storage capacity, which is helpful to form and repair oxygen vacancies on the $\mathrm{CeO}_{2}$ surface, binding adsorbates much more strongly than normal oxide sites. ${ }^{24}$ Therefore, the introduction of $\mathrm{CeO}_{2}$ onto $\mathrm{Co}-\mathrm{Bi}$ nanosheets will be beneficial for the formation of hydroperoxy species $\left(\mathrm{OOH}_{\mathrm{ad}}\right)$ on the surface of the hybrids owing to the high mobility of oxygen vacancies. Furthermore, the chemical synergistic effect between Co-Bi nanosheets and $\mathrm{CeO}_{2}$ would also improve the OER catalytic performance. Thus, the $\mathrm{CeO}_{2} / \mathrm{Co}-\mathrm{Bi}$ hybrids should be efficient candidates to improve the electrocatalytic activity for OER in neutral medium.

In this work, we report a room temperature chemical route to prepare $x \mathrm{CeO}_{2} / \mathrm{Co}-\mathrm{Bi}$ hybrids $\left(10 \mathrm{CeO}_{2} / \mathrm{Co}-\mathrm{Bi}, 20 \mathrm{CeO}_{2} / \mathrm{Co}-\mathrm{Bi}\right.$, $30 \mathrm{CeO}_{2} / \mathrm{Co}-\mathrm{Bi} ; x$ represents the amount of $\mathrm{CeO}_{2}$ ) through tuning the molar ratio of $\mathrm{Ce} / \mathrm{Co}$, and their OER catalytic activities were compared. It was found that $20 \mathrm{CeO}_{2} / \mathrm{Co}-\mathrm{Bi}$ exhibited the highest OER catalytic activity with an overpotential of $453 \mathrm{mV}$ at a current density of $10 \mathrm{~mA} \mathrm{~cm}{ }^{-2}$, Tafel slope of

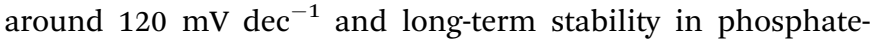
buffered saline (PBS) solution because of the good conductivity, mass transportation and strong synergetic coupling effects.

\section{Experimental}

All chemicals were commercially available and used without further purification. Cobalt nitrate hexahydrate $\left(\mathrm{Co}\left(\mathrm{NO}_{3}\right)_{2}-\right.$ $\left.\cdot 6 \mathrm{H}_{2} \mathrm{O}\right)$, cerium nitrate hexahydrate $\left(\mathrm{Ce}\left(\mathrm{NO}_{3}\right)_{3} \cdot 6 \mathrm{H}_{2} \mathrm{O}\right)$ and sodium borohydride $\left(\mathrm{NaBH}_{4}\right)$ were purchased from Sigma. Milli-Q water $(18.2 \mathrm{M} \Omega \mathrm{cm})$ was used in this work.

\subsection{Synthesis of $\mathrm{CeO}_{2} / \mathrm{Co}-\mathrm{Bi}$ composites}

The $\mathrm{CeO}_{2} / \mathrm{Co}-\mathrm{Bi}$ samples were prepared by a room temperature chemical synthesis method as illustrated in Fig. 1a. In particular, $n$ mmol $(n=0.1,0.2$ and 0.3$) \mathrm{Ce}\left(\mathrm{NO}_{3}\right)_{3} \cdot 6 \mathrm{H}_{2} \mathrm{O}$ and $(1-n)$ mmol $\mathrm{Co}\left(\mathrm{NO}_{3}\right)_{2} \cdot 6 \mathrm{H}_{2} \mathrm{O}$ were added into a flask with $100 \mathrm{ml}$ deionized water under continuous and vigorous stirring for complete dissolution (marked as A). Then, $5 \mathrm{~mL} \mathrm{NaBH}_{4}$ solution $\left(0.5 \mathrm{~mol} \mathrm{~L}^{-1}\right)$ was added to $\mathrm{A}$, and the mixed solution was kept at room temperature for $40 \mathrm{~min}$ under strong stirring; the solution gradually turned into black suspended solids (marked as B). The suspended products were collected by centrifugation and laved with deionized water and ethanol several times. The asprepared products were finally dried in a vacuum overnight for further characterization. Co-Bi hierarchical nanosheets were prepared by the same procedure but without using $\mathrm{Ce}\left(\mathrm{NO}_{3}\right)_{3} \cdot 6 \mathrm{H}_{2} \mathrm{O}$.

\subsection{Characterization}

The surface area was measured by nitrogen physisorption (Micromeritics, ASAP 2020 HD88) based on the Brunauer-
Emmett-Teller (BET) method. The phase evolution of the assynthesized nanostructures was monitored by powder X-ray diffraction (XRD). The XRD patterns with diffraction intensity versus $2 \theta$ were recorded with a Shimadzu X-ray diffractometer (Model 6000) using $\mathrm{Cu} \mathrm{K} \alpha$ radiation. X-ray photoelectron spectra (XPS) were acquired on a Thermo Scientific Model KAlpha with $\mathrm{Al} \mathrm{K} \alpha$ as the excitation source. Raman spectra were recorded at room temperature using an XY Dilor spectrograph equipped with a Spex CCD detector $(2000 \times 800$ pixels). Spectra were recorded in microconfiguration with a laser impact of $c a .1$ $\mu \mathrm{m}$ diameter. The excitation source was the $633 \mathrm{~nm}$ line of an argon laser at the power level of $5.4 \mathrm{~mW}$. Scanning electron microscopy (SEM) was performed on a Hitachi Su8010 scanning electron microscope. Transmission electron microscopy (TEM) studies were conducted on a Hitachi HT-7700 transmission electron microscope with an accelerating voltage of $120 \mathrm{kV}$. High-resolution TEM, selected area electron diffraction (SAED), electron energy loss spectroscopy (EELS), and energy-dispersive X-ray spectroscopy (EDS) were conducted on a JEOL JEM 2100F transmission electron microscope with an accelerating voltage of $200 \mathrm{kV}$.

\subsection{Electrochemical measurements}

Electrocatalytic activities assessed by linear sweep voltammetry (LSV) and chronoamperometry were measured on a CHI 660D electrochemical workstation (CH Instruments, Shanghai, China) with a standard three-electrode system in $0.1 \mathrm{M}$ PBS aqueous solution $(\mathrm{pH}=7.4)$. The counter and reference electrodes were platinum wire and standard $\mathrm{Ag} / \mathrm{AgCl}(3 \mathrm{M} \mathrm{KCl})$, respectively. The catalyst with a loading of $0.56 \mathrm{mg} \mathrm{cm}^{-2}$ on carbon fiber paper (CFP) was used as the working electrode. The scanning rate for LSV measurements was $5 \mathrm{mV} \mathrm{s}^{-1}$. Rotatingdisk electrode voltammograms were obtained at a scan rate of $10 \mathrm{mV} \mathrm{s}^{-1}$. Electrochemical impedance spectroscopy (EIS) was performed on the AUTOLAB PGSTAT204 electrochemical workstation in the frequency range from $0.01 \mathrm{~Hz}$ to $100 \mathrm{kHz}$ at an open circuit potential, with $10 \mathrm{mV}$ as the amplitude potential.

\section{Results and discussion}

The morphology and composition of the as-prepared products were characterized by SEM, TEM and XRD, as shown in Fig. 1. The SEM (Fig. 1b) and TEM (Fig. 1c) images of the as-prepared Co-Bi nanosheets show a hierarchical structure comprising aggregated ultrathin nanosheets. XRD patterns (Fig. 1c) show that $\mathrm{Co}-\mathrm{Bi}$ ultrathin nanosheets have no diffraction peaks, implying the presence of amorphous structures, which is in agreement with a previous report. ${ }^{13}$ The amorphous structure was further confirmed by selected area electron diffraction (SAED) as shown in Fig. 1e. Some new nanoparticles were observed to be uniformly coated on the surface of $\mathrm{Co}-\mathrm{Bi}$ nanosheets after introducing the source of Ce (Fig. 2a-c). In addition, the amount of the particles increases with the incremental amount of Ce source, but excess particles would destroy the structure of the Co-Bi nanosheets (Fig. 2a-c.). A new 

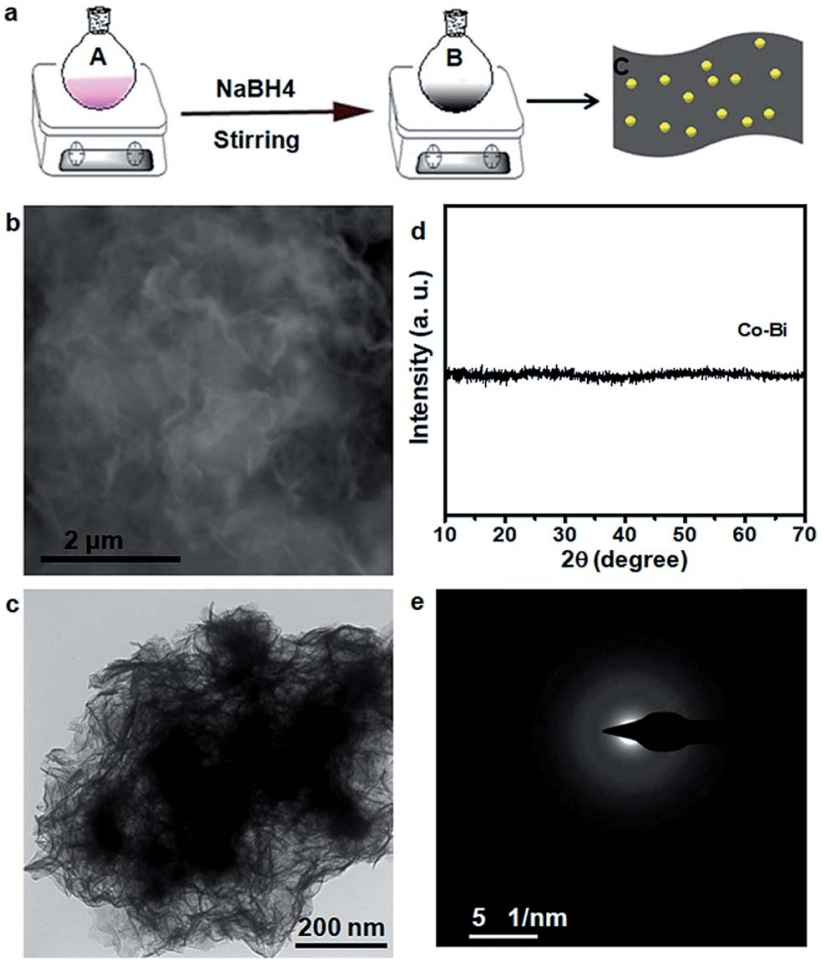

Fig. 1 (a) Schematic illustration of the synthesis of the $\mathrm{CeO}_{2} / \mathrm{Co}-\mathrm{Bi}$ hybrids by a room temperature chemical method. A refers to the solution consisting of $\mathrm{Co}\left(\mathrm{NO}_{3}\right)_{2} \cdot 6 \mathrm{H}_{2} \mathrm{O}$ and $\mathrm{Ce}\left(\mathrm{NO}_{3}\right)_{3} \cdot 6 \mathrm{H}_{2} \mathrm{O}$. B refers to the suspended products of $\mathrm{CeO}_{2} / \mathrm{Co}-\mathrm{Bi}$. C refers to the structure of $\mathrm{CeO}_{2} / \mathrm{Co}-\mathrm{Bi}$ hybrids. (b) SEM and (c) TEM images, (d) XRD patterns, and (e) SAED pattern of pure Co-Bi nanosheets.

diffraction peak at $33^{\circ}$ (Fig. 2d, marked by *), indexed to the (200) of $\mathrm{CeO}_{2},{ }^{24,26}$ was detected from $\mathrm{CeO}_{2} / \mathrm{Co}-\mathrm{Bi}$ composites compared to pure Co-Bi nanosheets, and its intensity increased with the increase in the Ce source (Fig. 1d). No more XRD peaks of $\mathrm{CeO}_{2}$ ( $\square$ represents the peaks of pure $\mathrm{CeO}_{2}$, JCPDS no. 340394) were detected due to the small size of $\mathrm{CeO}_{2}$ particles $(<5$ $\mathrm{nm}$ ), their good dispersibility on the nanosheets and the effect of the amorphous structure of Co-Bi nanosheets. Additionally, EDS mapping and EELS spectra show the presence and the homogeneous distribution of the elements $\mathrm{Co}, \mathrm{B}, \mathrm{O}$, and $\mathrm{Ce}$ in the as-prepared $20 \mathrm{CeO}_{2} / \mathrm{Co}-\mathrm{Bi}$ composite, as shown in Fig. S1 and $\mathrm{S} 2 \uparrow$ which depicts the K-edge of $\mathrm{B}$ at $188 \mathrm{eV},{ }^{23,28} \mathrm{~L}$-edges of $\mathrm{Co}$ at $780 \mathrm{eV}$ and M-edges of Ce at $890 \mathrm{eV} \cdot{ }^{29-31}$ In order to further analyse the compositions, we chose $20 \mathrm{CeO}_{2} / \mathrm{Co}-\mathrm{Bi}$ as a representative to be studied by HRTEM (Fig. 2e). The nanoparticles on the surface of the $\mathrm{Co}-\mathrm{Bi}$ nanosheets show a lattice fringe with a distance of $0.31 \mathrm{~nm}$, which was assigned to (111) of $\mathrm{CeO}_{2}$. The results demonstrate that the $\mathrm{CeO}_{2} / \mathrm{Co}-\mathrm{Bi}$ composites have been successfully prepared.

Raman spectroscopy was applied to further confirm the presence of $\mathrm{CeO}_{2}$ in the as-prepared composites because the $\mathrm{F}_{2 \mathrm{~g}}$ mode of $\mathrm{CeO}_{2}$ of the fluorite structure is Raman active at $465 \mathrm{~cm}^{-1} \cdot{ }^{32,33}$ Fig. 2f shows the Raman spectra collected from the composites (black line indicates pure Co-Bi nanosheets), and the intensity increases with the increase in the amount of
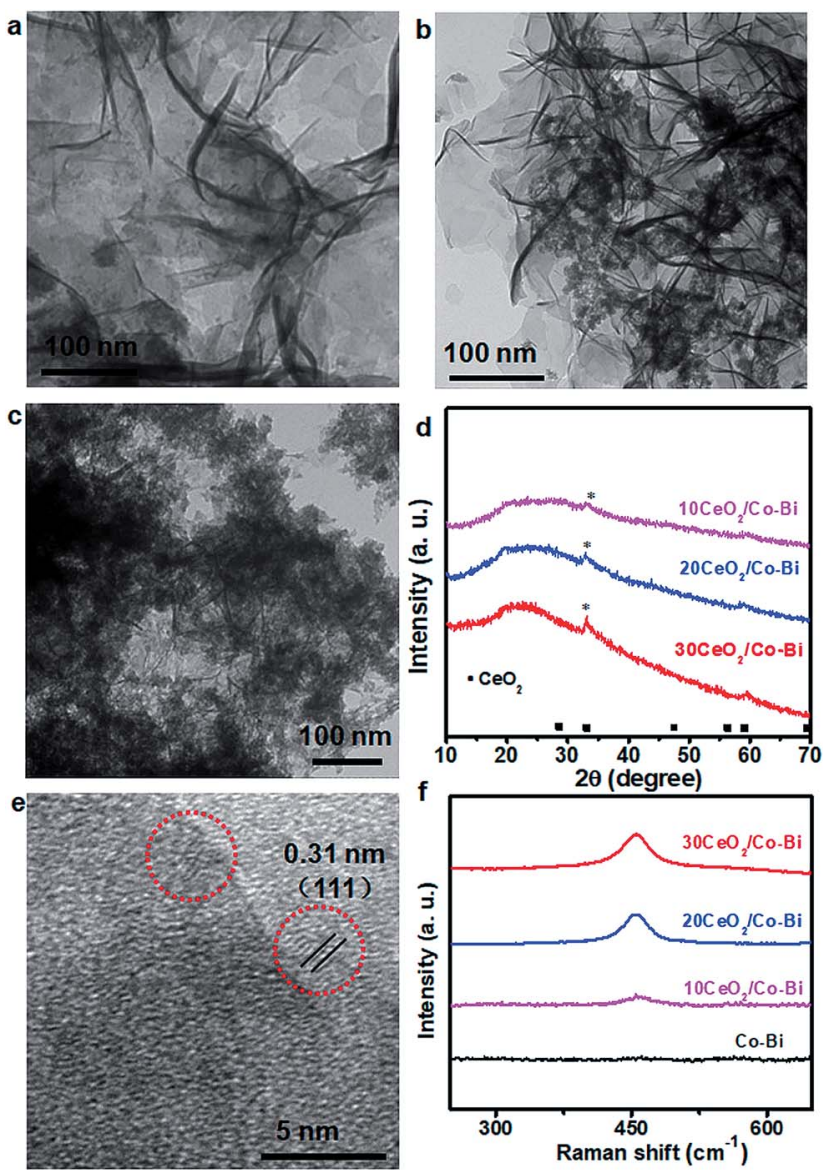

Fig. 2 Characterization of $\mathrm{CeO}_{2} / \mathrm{Co}-\mathrm{Bi}$ composites. TEM images (ac) and (d) XRD patterns of $10 \mathrm{CeO}_{2} / \mathrm{Co}-\mathrm{Bi}, 20 \mathrm{CeO}_{2} / \mathrm{Co}-\mathrm{Bi}$ and $30 \mathrm{CeO}_{2} / \mathrm{Co}-\mathrm{Bi}$, respectively. (e) HRTEM images of $20 \mathrm{CeO}_{2} / \mathrm{Co}-\mathrm{Bi}$ and (f) Raman spectra for $\mathrm{Co}-\mathrm{Bi}, 10 \mathrm{CeO}_{2} / \mathrm{Co}-\mathrm{Bi}, 20 \mathrm{CeO}_{2} / \mathrm{Co}-\mathrm{Bi}$ and $30 \mathrm{CeO}_{2} / \mathrm{Co}-\mathrm{Bi}$

$\mathrm{CeO}_{2}$. The $\sim 10 \mathrm{~cm}^{-1}$ shift of Raman frequency between our samples and literature reports ${ }^{33-35}$ is attributed to the size effects, which is consistent with a previous report. ${ }^{36}$

The specific surface area of the as-grown samples was measured from the standard BET procedure (Fig. S3 $\dagger$ ). The BET surface areas of $10 \mathrm{CeO}_{2} / \mathrm{Co}-\mathrm{Bi}, 20 \mathrm{CeO}_{2} / \mathrm{Co}-\mathrm{Bi}$ and $30 \mathrm{CeO}_{2} / \mathrm{Co}-$ Bi were $249.8 \mathrm{~m}^{2} \mathrm{~g}^{-1}, 290.2 \mathrm{~m}^{2} \mathrm{~g}^{-1}$ and $330.1 \mathrm{~m}^{2} \mathrm{~g}^{-1}$, respectively, much higher than that of pure Co-Bi nanosheets (134.0 $\left.\mathrm{m}^{2} \mathrm{~g}^{-1}\right)$. It is generally accepted that a larger surface area means better catalytic activity.

To evaluate the OER activities of the $\mathrm{CeO}_{2} / \mathrm{Co}-\mathrm{Bi}$ composites, the catalysts were loaded onto the CFP electrode with a density of $0.56 \mathrm{mg} \mathrm{cm}^{-2}$ by drop casting. The potentials reported in this work were calibrated to the RHE using the following equation: $E(\mathrm{RHE})=E(\mathrm{Ag} / \mathrm{AgCl})+(0.197+0.0591 \times \mathrm{pH}) \mathrm{V} .{ }^{13}$ Fig. 3a shows the LSV curves of a bare CFP substrate, $\mathrm{Co}-\mathrm{Bi}, 10 \mathrm{CeO}_{2} / \mathrm{Co}-\mathrm{Bi}$, $20 \mathrm{CeO}_{2} / \mathrm{Co}-\mathrm{Bi}, 30 \mathrm{CeO}_{2} / \mathrm{Co}-\mathrm{Bi}$ and commercial $\mathrm{RuO}_{2} / \mathrm{C}$ electrodes in 0.1 M PBS. Compared to the strong catalytic current from electrodes with catalysts, almost no current density from the bare CFP substrate was detected at $1.8 \mathrm{~V}$ (vs. RHE), indicating that $\mathrm{CFP}$ is inactive towards $\mathrm{O}_{2}$ evolution and 

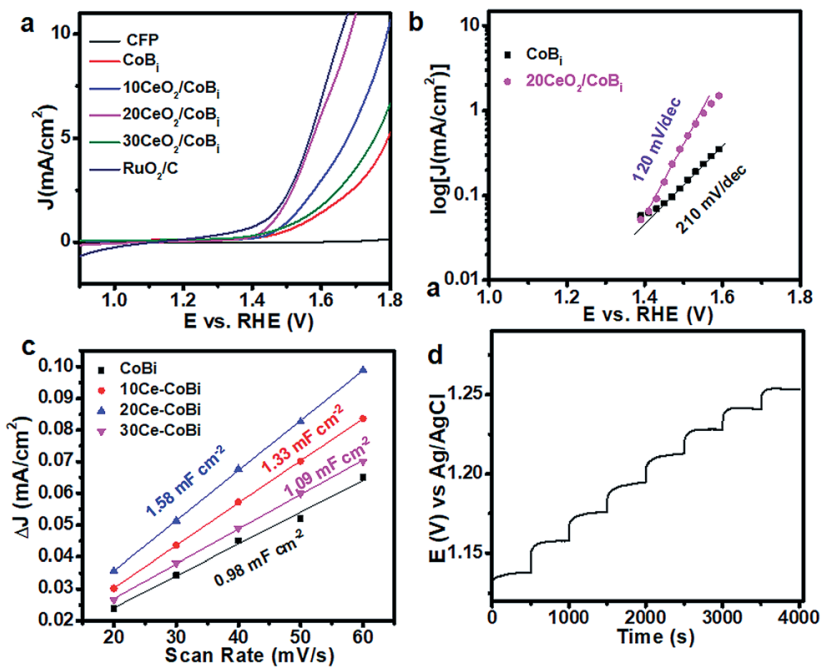

Fig. 3 (a) Linear sweep voltammograms of all catalytic (CFP, Co-Bi, $10 \mathrm{CeO}_{2} / \mathrm{Co}-\mathrm{Bi}, 20 \mathrm{CeO}_{2} / \mathrm{Co}-\mathrm{Bi}, 30 \mathrm{CeO}_{2} / \mathrm{Co}-\mathrm{Bi}$ and commercial $\mathrm{RuO}_{2} / \mathrm{C}$ ) electrodes in $0.1 \mathrm{M}$ PBS without iR correction; (b) Tafel slope for $\mathrm{Co}-\mathrm{Bi}$ and $20 \mathrm{CeO}_{2} / \mathrm{Co}-\mathrm{Bi}$; (c) multi-current process of $20 \mathrm{CeO}_{2} /$ $\mathrm{Co}-\mathrm{Bi}$ in $0.1 \mathrm{M}$ PBS. The current density started at $2 \mathrm{~mA} \mathrm{~cm}^{-2}$ and ended at $9 \mathrm{~mA} \mathrm{~cm}^{-2}$, with an increment of about $1 \mathrm{~mA} \mathrm{~cm}^{-2}$ per $500 \mathrm{~s}$, without $i R$ correction and (d) charging current density differences plotted versus scan rate. The linear slope, equivalent to twice the double-layer capacitance $C_{d l}$, was used to represent the ECSA.

a background correction for the CFP support is unnecessary for all catalytic electrodes. The overpotentials at the specified current density of $5 \mathrm{~mA} \mathrm{~cm}{ }^{-2}$, the current densities at $1.8 \mathrm{~V}(v s$. RHE) and the Tafel slopes of all catalysts, obtained in $0.1 \mathrm{M}$ PBS, are summarized in Table 1 . The $20 \mathrm{CeO}_{2} / \mathrm{Co}-\mathrm{Bi}$ electrode demands an overpotential of only $346 \mathrm{mV}$ to deliver a catalytic current density of $5 \mathrm{~mA} \mathrm{~cm} \mathrm{~cm}^{-2}$, much lower than those of $10 \mathrm{CeO}_{2} / \mathrm{Co}-\mathrm{Bi}(446 \mathrm{mV})$ and $30 \mathrm{CeO}_{2} / \mathrm{Co}-\mathrm{Bi}(525 \mathrm{mV})$ under the same catalytic current density, respectively. For comparison, the electrocatalytic OER activity of Co-Bi nanosheets was measured as well, obtaining an overpotential of $560 \mathrm{mV}$ at a current density of $5 \mathrm{~mA} \mathrm{~cm}{ }^{-2}$, much higher than those of $\mathrm{CeO}_{2} / \mathrm{Co}-\mathrm{Bi}$ composite electrodes. In addition, we obtained an overpotential of $453 \mathrm{mV}$ from the $20 \mathrm{CeO}_{2} / \mathrm{Co}-\mathrm{Bi}$ electrode at a current density of $10 \mathrm{~mA} \mathrm{~cm}{ }^{-2}$, which is close to that of $\mathrm{RuO}_{2} / \mathrm{C}(430 \mathrm{mV})$ and also comparable to the values reported previously under neutral conditions (Table S1 $\dagger$ ). ${ }^{13,14,23,37-44}$ The current density of the $20 \mathrm{CeO}_{2} / \mathrm{Co}-\mathrm{Bi}$ electrode at $1.8 \mathrm{~V}$ (vs. RHE) was $19.2 \mathrm{~mA} \mathrm{~cm}^{-2}$, not only much larger than $11.4,7.2$, and $5.7 \mathrm{~mA} \mathrm{~cm}^{-2}$ obtained from $10 \mathrm{CeO}_{2} / \mathrm{Co}-\mathrm{Bi}, 30 \mathrm{CeO}_{2} / \mathrm{Co}-\mathrm{Bi}$ and $\mathrm{Co}-\mathrm{Bi}$ electrodes, respectively, but also superior to those of $\mathrm{A}-\mathrm{CoS}_{4.6} \mathrm{O}_{0.6}$ PNCs (4.59 $\left.\mathrm{mA} \mathrm{cm}{ }^{-2}\right)$ and $\mathrm{Co}-\mathrm{Bi} \mathrm{NS} / \mathrm{G}\left(14.4 \mathrm{~mA} \mathrm{~cm}^{-2}\right)$ measured at the same potential $\left(1.8 \mathrm{~V}\right.$ vs. RHE). ${ }^{13,45}$ All these results indicate the high OER catalytic activity of the $20 \mathrm{CeO}_{2} / \mathrm{Co}-\mathrm{Bi}$ hybrid under neutral conditions.

We also fitted the polarization curves (Fig. 3a) using the Tafel equation $\eta=b \log \left(j / j_{0}\right)$, where $\eta$ represents the overpotential, $b$ is the Tafel slope, $j$ refers to the current density and $j_{0}$ is the exchange current density. ${ }^{9}$ Accordingly, the derived Tafel slope of $120 \mathrm{mV} \mathrm{dec}{ }^{-1}$ from $20 \mathrm{CeO}_{2} / \mathrm{Co}-\mathrm{Bi}$ was much lower than the slope of $210 \mathrm{mV} \mathrm{dec}^{-1}$ from Co-Bi (Fig. 3b) and close to or even lower than the values measured from other reported catalysts, including 3D Ni-Bi nanowire arrays $(107 \mathrm{mV}$ $\left.\mathrm{dec}^{-1}\right),{ }^{14} \mathrm{Co}-\mathrm{Bi} /$ graphene composites $\left(160 \mathrm{mV} \mathrm{dec}{ }^{-1}\right),{ }^{13} \mathrm{Ni}-\mathrm{Bi} /$ RGO $\left(176 \mathrm{mV} \mathrm{dec}^{-1}\right)^{46}$ and 3D Co-Pi nanowires $(187 \mathrm{mV}$ $\left.\mathrm{dec}^{-1}\right),{ }^{12}$ suggesting the high OER activity of $20 \mathrm{CeO}_{2} / \mathrm{Co}-\mathrm{Bi}$. Additionally, Fig. $3 \mathrm{c}$ shows a multi-step chronopotentiometric curve for the $20 \mathrm{CeO}_{2} / \mathrm{Co}-\mathrm{Bi}$ composite electrode at current densities from 2 to $9 \mathrm{~mA} \mathrm{~cm}{ }^{-2}$ (ca. $1 \mathrm{~mA} \mathrm{~cm}^{-2}$ per $500 \mathrm{~s}$ ). The potential immediately levels off at $1.13 \mathrm{~V}(v s . \mathrm{Ag} / \mathrm{AgCl})$ at the initial current value and remains unchanged for $500 \mathrm{~s}$, and the other steps also show similar results, implying good conductivity, mass transportation, and mechanical robustness of this electrode..$^{47,48}$ These results further demonstrate that $20 \mathrm{CeO}_{2} /$ Co-Bi composite electrodes have excellent OER catalytic performance.

The reasons for the enhancement of electrochemical catalytic OER activity of $\mathrm{CeO}_{2} / \mathrm{Co}-\mathrm{Bi}$ compared to that of $\mathrm{Co}-\mathrm{Bi}$ are summarised as follows. First, $\mathrm{CeO}_{2} / \mathrm{Co}-\mathrm{Bi}$ composites have a much larger surface area than $\mathrm{Co}-\mathrm{Bi}$ and thus more catalytically active sites, which can significantly improve the OER process (Table 1). Although the surface area of the $30 \mathrm{CeO}_{2} / \mathrm{Co}-$ $\mathrm{Bi}$ composite $\left(330.1 \mathrm{~m}^{2} \mathrm{~g}^{-1}\right)$ is larger than that of the $20 \mathrm{CeO}_{2} /$ Co-Bi composite $\left(290.2 \mathrm{~m}^{2} \mathrm{~g}^{-1}\right), 30 \mathrm{CeO}_{2} / \mathrm{Co}-\mathrm{Bi}$ shows worse OER performance than $20 \mathrm{CeO}_{2} / \mathrm{Co}-\mathrm{Bi}$ because the nanosheet structure of $30 \mathrm{CeO}_{2} / \mathrm{Co}-\mathrm{Bi}$ has been destroyed (Fig. 2c). Electrochemical impedance spectroscopy (EIS) was used to further investigate the detailed characteristics of $\mathrm{Co}-\mathrm{Bi}, 10 \mathrm{CeO}_{2} / \mathrm{Co}-\mathrm{Bi}$, $20 \mathrm{CeO}_{2} / \mathrm{Co}-\mathrm{Bi}$, and $30 \mathrm{CeO}_{2} / \mathrm{Co}-\mathrm{Bi}$ as capacitive electrodes (see ESI Fig. S4 $\dagger$ ). The semicircular characteristic of EIS curves suggests the smallest charge transfer and the best charge conductivity of $20 \mathrm{CeO}_{2} / \mathrm{Co}-\mathrm{Bi}$ compared to those of other catalysts $\left(\mathrm{Co}-\mathrm{Bi}, 10 \mathrm{CeO}_{2} / \mathrm{Co}-\mathrm{Bi}\right.$ and $\left.30 \mathrm{CeO}_{2} / \mathrm{Co}-\mathrm{Bi}\right)$ and thus the highest OER catalytic activity among the samples.

Table 1 Summary of the OER electrocatalytic activities of the samples in phosphate-buffered saline solution $(\mathrm{pH}=7.4)$

\begin{tabular}{llclll}
\hline Sample & $\eta^{a} @ 5\left(\mathrm{~mA} \mathrm{~cm}{ }^{-2}\right)$ & $J^{b} @ 1.8 \mathrm{~V}(v s . \mathrm{RHE})$ & Tafel slope $\left(\mathrm{mV} \mathrm{dec}^{-1}\right)$ & BET surface ${\operatorname{area~}\left(\mathrm{m}^{2} \mathrm{~g}^{-1}\right)}^{\left.\mathrm{Capacitance}_{(\mathrm{mF} \mathrm{cm}}{ }^{-2}\right)}$ \\
\hline $\mathrm{Co}-\mathrm{Bi}$ & 560 & 5.7 & 210 & 134.0 & 0.98 \\
$10 \mathrm{CeO}_{2} / \mathrm{Co}-\mathrm{Bi}$ & 446 & 11.4 & 160 & 249.8 & 1.33 \\
$20 \mathrm{CeO}_{2} / \mathrm{Co}-\mathrm{Bi}$ & 346 & 19.2 & 120 & 290.2 & 1.58 \\
$30 \mathrm{CeO}_{2} / \mathrm{Co}-\mathrm{Bi}$ & 525 & 7.2 & 198 & 330.1 & 1.09
\end{tabular}

${ }^{a} \eta$ refers to the overpotential $(\mathrm{mV})$ of the samples at a current density of $5 \mathrm{~mA} \mathrm{~cm}{ }^{-2} \cdot{ }^{b} J$ refers to the current densities of the catalysts at a specific overpotential. 
Second, $\mathrm{CeO}_{2} / \mathrm{Co}-\mathrm{Bi}$ composites have a larger electrochemical surface area (ECSA) compared to Co-Bi. A larger ECSA means more accessible surface permeation and thus higher catalytic activity. According to the $\mathrm{CV}$ curves of $\mathrm{Co}-\mathrm{Bi}, 10 \mathrm{CeO}_{2} /$ $\mathrm{Co}-\mathrm{Bi}, 20 \mathrm{CeO}_{2} / \mathrm{Co}-\mathrm{Bi}$, and $30 \mathrm{CeO}_{2} / \mathrm{Co}-\mathrm{Bi}$ (see ESI Fig. S5 $\dagger$ ), capacitive currents as a function of the scan rate of the samples are plotted in Fig. 3c. The double-layer capacitance $\left(C_{\mathrm{dl}}\right)$ of each sample was estimated from the slope of the corresponding linear fitting, and therefore, one can obtain the value of ECSA, which is double the $C_{\mathrm{dl}}$ value. ${ }^{45}$ Obviously, $20 \mathrm{CeO}_{2} / \mathrm{Co}-\mathrm{Bi}$ has the highest $C_{\mathrm{dl}}$ among the four samples (Fig. 3d), and thus, the largest ECSA contributes to the best catalytic performance.

Lastly, in order to investigate the strong electronic interactions between $\mathrm{Co}-\mathrm{Bi}$ and $\mathrm{CeO}_{2}$, XPS was applied to characterize pure $\mathrm{CeO}_{2}$, Co-Bi, 20CeO $/ \mathrm{Co}-\mathrm{Bi}, 20 \mathrm{CeO}_{2} / \mathrm{Co}-\mathrm{Bi}$ and $30 \mathrm{CeO}_{2} /$ $\mathrm{Co}-\mathrm{Bi}$ hybrids, and the results are plotted in Figs 4, S6 and $\mathrm{S} 7 . \dagger$ All the spectra were referenced to the aliphatic carbon at a binding energy (BE) of $284.5 \mathrm{eV}$. The survey spectra of $20 \mathrm{CeO}_{2} /$ Co-Bi showed the presence of $\mathrm{Co}, \mathrm{B}, \mathrm{O}$ and $\mathrm{Ce}$, but no Ce was detected from Co-Bi nanosheets (Fig. 4c), consistent with EDS and EELS results (see ESI Fig. S1 and S2†).

As shown in Fig. 4b, the peak at $192.5 \mathrm{eV}$ is assigned to the core level of $\mathrm{B}^{3+}$ in borate species. The $\mathrm{O} 1 \mathrm{~s}$ spectra of pure $\mathrm{CeO}_{2}, \mathrm{Co}-\mathrm{Bi}, 10 \mathrm{CeO}_{2} / \mathrm{Co}-\mathrm{Bi}, 20 \mathrm{CeO}_{2} / \mathrm{Co}-\mathrm{Bi}$ and $20 \mathrm{CeO}_{2} / \mathrm{Co}-\mathrm{Bi}$ are shown in Fig. $\mathrm{S} 8 . \dagger$ The peak at $529.4 \mathrm{eV}$ is ascribed to the $\mathrm{O}$ $1 \mathrm{~s}$ of $\mathrm{Ce}-\mathrm{O}$ and that at $531.9 \mathrm{eV}$ corresponds to $\mathrm{O} 1 \mathrm{~s}$ of the central oxygen atoms in borate. ${ }^{25,49}$ For high-resolution Ce $3 \mathrm{~d}$ spectra of pure $\mathrm{CeO}_{2}$ (Fig. 4c), the peaks located at 896-926 eV correspond to $\mathrm{Ce} 3 \mathrm{~d}_{3 / 2}$, and the peaks located at $880-892 \mathrm{eV}$ are consistent with $\mathrm{Ce} 3 \mathrm{~d}_{5 / 2}$, which demonstrated the coexistence of $\mathrm{Ce}^{3+}$ and $\mathrm{Ce}^{4+}$ in $\mathrm{CeO}_{2}$. However, after introducing $\mathrm{CeO}_{2} \mathrm{NPs}$ onto the Co-Bi nanosheets, the ratio of $\mathrm{Ce}^{3+}: \mathrm{Ce}^{4+}$ in the $\mathrm{CeO}_{2} /$ Co-Bi hybrid changed compared with that of pure $\mathrm{CeO}_{2}$, suggesting that the valence states of $\mathrm{Ce}$ in the $\mathrm{CeO}_{2} / \mathrm{Co}-\mathrm{Bi}$ hybrid have rearranged. ${ }^{25,26}$ As shown in Fig. 4d, the binding energy of Co 2 p from $20 \mathrm{CeO}_{2} / \mathrm{Co}-\mathrm{Bi}$ showed an $\sim 0.5 \mathrm{eV}$ negative shift
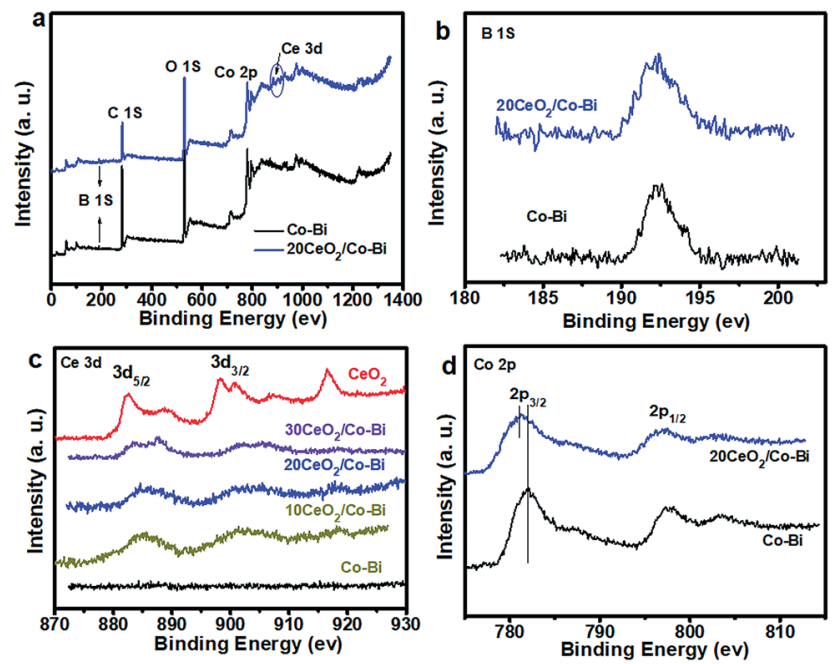

Fig. 4 XPS spectra of $\mathrm{Co}-\mathrm{Bi}$ and $2 \mathrm{OCeO}_{2} / \mathrm{Co}-\mathrm{Bi}$ composites (a), and high-resolution XPS spectra for B (b), Ce (c) and Co (d).
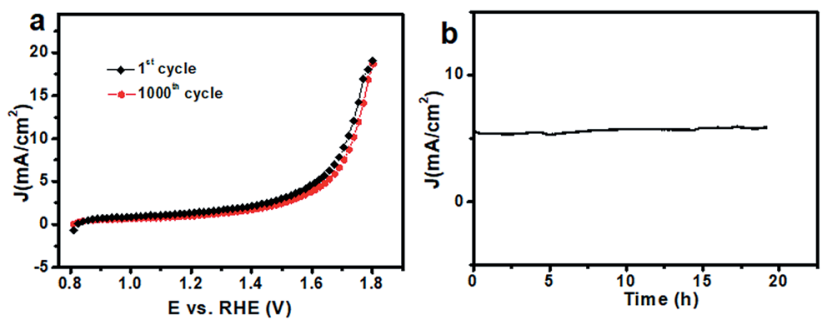

Fig. 5 (a) Polarization curves of $2 \mathrm{OCeO}_{2} / \mathrm{Co}-\mathrm{Bi}$ before and after 1000 $\mathrm{CV}$ cycles in PBS; (b) chronoamperometric response of the asprepared $20 \mathrm{CeO}_{2} / \mathrm{Co}-\mathrm{Bi}$ composite recorded at a constant potential of $1.65 \mathrm{~V}$ vs. RHE.

compared to that of pure $\mathrm{Co}-\mathrm{Bi}$ nanosheets, presumably caused by the electron transfer from $\mathrm{CeO}_{2}$ to $\mathrm{Co}-\mathrm{Bi}$, and it is also found that there is a more negative shift of the $\mathrm{CeO}_{2} / \mathrm{Co}-\mathrm{Bi}$ hybrid with the increase in the amount of $\mathrm{CeO}_{2}$ (Fig. S7†). This phenomenon has been demonstrated in previous reports. ${ }^{\mathbf{2 4 , 2 6 , 5 0}}$ Moreover, this modification in the electronic structure makes $\mathrm{CeO}_{2}$ more acidic (Lewis acid) and thus facilitates the activation of $\mathrm{H}_{2} \mathrm{O}$ molecules (Lewis base), benefiting the formation of $\mathrm{OOH}_{\mathrm{ad}}$ on the surface of the composites and facilitating the OER process and thus enhancement of the efficiency of water oxidation. ${ }^{24}$ Additionally, the increase in the charge conductivity of $\mathrm{CeO}_{2} / \mathrm{Co}-\mathrm{Bi}$ after introducing $\mathrm{CeO}_{2}$ indicates faster charge transfer during the catalytic reaction, improving the catalytic efficiency of water oxidation (see ESI Fig. S6 $\dagger$ ). After introducing the small $\mathrm{CeO}_{2}$ nanoparticles, the hybrids display a larger surface area, smaller charge transfer, better charge conductivity and stronger synergistic effects. All these advantages of the hybrids together are responsible for the good OER catalytic activity of the new $\mathrm{CeO}_{2} / \mathrm{Co}-\mathrm{Bi}$ catalysts.

Besides the catalytic activity, the stability of the catalyst, another major concern in designing cost-effective OER catalysts, was investigated as well. After $1000 \mathrm{CV}$ cycles in $0.1 \mathrm{M}$ PBS (Fig. S8†), there was almost no obvious loss in catalytic current (Fig. 5a), suggesting its superior stability. Additionally, the stability of the $20 \mathrm{CeO}_{2} / \mathrm{Co}-\mathrm{Bi}$ composite was determined by measuring chronoamperometric responses $(i-t)$ at $1.65 \mathrm{~V}(v s$. RHE) in 0.1 M PBS. During the measurements, the working electrode was continuously rotating at $1600 \mathrm{rpm}$ to remove the generated $\mathrm{O}_{2}$ bubbles. As shown in Fig. 5b, the stabilized current density indicates no obvious deactivation of the $20 \mathrm{CeO}_{2} / \mathrm{Co}-\mathrm{Bi}$ composite over $19 \mathrm{~h}$. The durability test of the $20 \mathrm{CeO}_{2} / \mathrm{Co}-\mathrm{Bi}$ electrode under higher current density was also performed, as shown in Fig. S9. $\dagger$ The current density of the $20 \mathrm{CeO}_{2} / \mathrm{Co}-\mathrm{Bi}$ composite over $30 \mathrm{~h}$ was only slightly attenuated. The results suggest that the $20 \mathrm{CeO}_{2} / \mathrm{Co}-\mathrm{Bi}$ composite exhibits good catalytic stability under neutral conditions.

\section{Conclusions}

In summary, we have successfully synthesised $\mathrm{CeO}_{2} / \mathrm{Co}-\mathrm{Bi}$ composites by facile chemical methods at room temperature. The larger surface area, smaller charge transfer, better charge conductivity and stronger synergistic effects obtained after 
introducing $\mathrm{CeO}_{2}$ nanoparticles are responsible for the good OER catalytic activity of these new $\mathrm{CeO}_{2} / \mathrm{Co}-\mathrm{Bi}$ composite catalysts. The $20 \mathrm{CeO}_{2} / \mathrm{Co}-\mathrm{Bi}$ composite exhibits outstanding OER catalytic activity with an overpotential of $453 \mathrm{mV}$ at a current density of $10 \mathrm{~mA} \mathrm{~cm}{ }^{-2}$, Tafel slope of around $120 \mathrm{mV}$ $\mathrm{dec}^{-1}$ and long-term stability in neutral medium, promising for practical application in the electrolysis of water.

\section{Conflicts of interest}

There are no conflicts to declare.

\section{Acknowledgements}

This work was supported by the China Postdoctoral Science Foundation (2017M622630) and the National Natural Science Foundation of China (51420105002 and 51672193).

\section{Notes and references}

1 T. R. Cook, D. K. Dogutan, S. Y. Reece, Y. Surendranath, T. S. Teets and D. G. Nocera, Chem. Rev., 2010, 110, 64746502.

2 M. G. Walter, E. L. Warren, J. R. McKone, S. W. Boettcher, Q. Mi, E. A. Santori and N. S. Lewis, Chem. Rev., 2010, 110, 6446-6473.

3 L. Hammarström and S. Hammes-Schiffe, Acc. Chem. Res., 2009, 1859-1860.

4 R. F. Service, Science, 2009, 324, 1257.

5 J. Li, M. Yan, X. Zhou, Z. Q. Huang, Z. Xia, C. R. Chang, Y. Ma and Y. Qu, Adv. Funct. Mater., 2016, 26, 6785-6796.

6 N. S. Lewis and D. G. Nocera, Proc. Natl. Acad. Sci. U. S. A., 2006, 103, 15729-15735.

7 W. Gao, M. Yan, H.-Y. Cheung, Z. Xia, X. Zhou, Y. Qin, C.-Y. Wong, J. C. Ho, C.-R. Chang and Y. Qu, Nano Energy, 2017, 38, 290-296.

8 X. Zhou, Z. Xia, Z. Zhang, Y. Ma and Y. Qu, J. Mater. Chem. A, 2014, 2, 11799-11806.

9 X. Zhou, Z. Xia, Z. Tian, Y. Ma and Y. Qu, J. Mater. Chem. A, 2015, 3, 8107-8114.

10 R. Ge, M. Ma, X. Ren, F. Qu, Z. Liu, G. Du, A. M. Asiri, L. Chen, B. Zheng and X. Sun, Chem. Commun., 2017, 53, 7812-7815.

11 T. Liu, L. Xie, J. Yang, R. Kong, G. Du, A. M. Asiri, X. Sun and L. Chen, ChemElectroChem, 2017, 4, 1840-1845.

12 L. Xie, R. Zhang, L. Cui, D. Liu, S. Hao, Y. Ma, G. Du, A. M. Asiri and X. Sun, Angew. Chem., Int. Ed., 2017, 56, 1064-1068.

13 P. Chen, K. Xu, T. Zhou, Y. Tong, J. Wu, H. Cheng, X. Lu, H. Ding, C. Wu and Y. Xie, Angew. Chem., Int. Ed., 2016, 55, 2488-2492.

14 X. Ji, L. Cui, D. Liu, S. Hao, J. Liu, F. Qu, Y. Ma, G. Du, A. M. Asiri and X. Sun, Chem. Commun., 2017, 53, 3070-3073.

15 M. W. Kanan and D. G. Nocera, Science, 2008, 321, 10721075.
16 P. Li, R. Zhao, H. Chen, H. Wang, P. Wei, H. Huang, Q. Liu, T. Li, X. Shi, Y. Zhang, M. Liu and X. Sun, Small, 2019, 15, 1805103.

17 D. G. Nocera, Acc. Chem. Res., 2012, 45, 767-776.

18 D. G. Nocera, Acc. Chem. Res., 2017, 50, 616-619.

19 M. Dincă, Y. Surendranath and D. G. Nocera, Proc. Natl. Acad. Sci. U. S. A., 2010, 107, 10337-10341.

20 Y. Surendranath, M. W. Kanan and D. G. Nocera, J. Am. Chem. Soc., 2010, 132, 16501-16509.

21 L. Xie, F. Qu, Z. Liu, X. Ren, S. Hao, R. Ge, G. Du, A. M. Asiri, X. Sun and L. Chen, J. Mater. Chem. A, 2017, 5, 7806-7810.

22 L. Yang, D. Liu, S. Hao, R. Kong, A. M. Asiri, C. Zhang and X. Sun, J. Mater. Chem. A, 2017, 5, 7305-7308.

23 C. Xie, Y. Wang, D. Yan, L. Tao and S. Wang, Nanoscale, 2017, 9, 16059-16065.

24 Y. R. Zheng, M. R. Gao, Q. Gao, H. H. Li, J. Xu, Z. Y. Wu and S. H. Yu, Small, 2015, 11, 182-188.

25 J. X. Feng, S. H. Ye, H. Xu, Y. X. Tong and G. R. Li, Adv. Mater., 2016, 28, 4698-4703.

26 Z. Liu, N. Li, H. Zhao, Y. Zhang, Y. Huang, Z. Yin and Y. Du, Chem. Sci., 2017, 8, 3211-3217.

27 W. Gao, D. Wen, J. Ho and Y. Qu, Mater. Today Chem., 2019, 12, 266-281.

28 Y. C. Zhu, Y. Bando and R. Z. Ma, Adv. Mater., 2003, 15, 13771379.

29 X. Liu, W. Wei, Q. Yuan, X. Zhang, N. Li, Y. Du, G. Ma, C. Yan and D. Ma, Chem. Commun., 2012, 48, 3155-3157.

30 P. Chen, K. Xu, Y. Tong, X. Li, S. Tao, Z. Fang, W. Chu, X. Wu and C. Wu, Inorg. Chem. Front., 2016, 3, 236-242.

31 Z. Zhang, W. Sigle, M. Rühle, E. Jud and L. J. Gauckler, Acta Mater., 2007, 55, 2907-2917.

32 W. Weber, K. Hass and J. McBride, Phys. Rev. B: Condens. Matter Mater. Phys., 1993, 48, 178.

33 J. E. Spanier, R. D. Robinson, F. Zhang, S.-W. Chan and I. P. Herman, Phys. Rev. B: Condens. Matter Mater. Phys., 2001, 64, 245407.

34 Z. Wu, M. Li, J. Howe, H. M. Meyer III and S. H. Overbury, Langmuir, 2010, 26, 16595-16606.

35 F. Zhang, S.-W. Chan, J. E. Spanier, E. Apak, Q. Jin, R. D. Robinson and I. P. Herman, Appl. Phys. Lett., 2002, 80, 127-129.

36 Z. Dohčević-Mitrović, M. Šćepanović, M. Grujić-Brojčin, Z. Popović, S. Bošković, B. Matović, M. Zinkevich and F. Aldinger, Solid State Commun., 2006, 137, 387-390.

37 H. S. Ahn and T. D. Tilley, Adv. Funct. Mater., 2013, 23, 227233.

38 K. Jin, J. Park, J. Lee, K. D. Yang, G. K. Pradhan, U. Sim, D. Jeong, H. L. Jang, S. Park and D. Kim, J. Am. Chem. Soc., 2014, 136, 7435-7443.

39 J. Park, H. Kim, K. Jin, B. J. Lee, Y.-S. Park, H. Kim, I. Park, K. D. Yang, H.-Y. Jeong and J. Kim, J. Am. Chem. Soc., 2014, 136, 4201-4211.

40 J. Tian, H. Li, A. M. Asiri, A. O. Al-Youbi and X. Sun, Small, 2013, 9, 2709-2714.

41 Y. Wu, M. Chen, Y. Han, H. Luo, X. Su, M. T. Zhang, X. Lin, J. Sun, L. Wang and L. Deng, Angew. Chem., Int. Ed., 2015, 54, 4870-4875. 
42 Y. Zhang, B. Cui, C. Zhao, H. Lin and J. Li, Phys. Chem. Chem. Phys., 2013, 15, 7363-7369.

43 D. Jeong, K. Jin, S. E. Jerng, H. Seo, D. Kim, S. H. Nahm, S. H. Kim and K. T. Nam, ACS Catal., 2015, 5, 4624-4628.

44 K. Jin, A. Chu, J. Park, D. Jeong, S. E. Jerng, U. Sim, H.-Y. Jeong, C. W. Lee, Y.-S. Park and K. D. Yang, Sci. Rep., 2015, 5, 10279.

45 P. Cai, J. Huang, J. Chen and Z. Wen, Angew. Chem., Int. Ed., 2017, 129, 4936-4939.
46 X. Cao, L. Cui, X. Wang, W. Yang and J. Liu, ChemCatChem, 2018, 10, 2826-2832.

47 C. Tang, N. Cheng, Z. Pu, W. Xing and X. Sun, Angew. Chem., Int. Ed., 2015, 127, 9483-9487.

48 X. Lu and C. Zhao, Nat. Commun., 2015, 6, 6616.

49 X. Ren, R. Ge, Y. Zhang, D. Liu, D. Wu, X. Sun, B. Du and Q. Wei, J. Mater. Chem. A, 2017, 5, 7291-7294.

50 M.-R. Gao, Y.-F. Xu, J. Jiang, Y.-R. Zheng and S.-H. Yu, J. Am. Chem. Soc., 2012, 134, 2930-2933. 